\title{
Quando é Cenografia?
}

\author{
João Carlos Machado \\ Universidade Federal do Rio Grande do Sul - UFRGS, Porto Alegre/RS, Brasil \\ E-mail: chicomachado06@uol.com.br
}

\section{Resumo}

A partir de questões levantadas nas experiências artísticas e de pesquisa do autor e nas recentes edições das Quadrienais de Praga, o texto trata de algumas possíveis definições dos conceitos de cenografia, performance, performatividade e teatralidade, buscando estabelecer distinções e aproximações entre as artes cênicas e as artes visuais, principalmente no campo da escultura. Para tanto são analisadas questões levantadas por autores como Rosalind Krauss e Josette Féral, entre outros, pertinentes às concepções culturalmente construídas destes campos e conceitos, bem como aos modos de pensar o fazer e os processos criativos destas áreas.

Palavras-chave

Cenografia. Teatralidade. Performance. Escultura.
From questions raised in the the author's artistic and research experiences and recent editions of the Prague Quadrennials, the text deals with some possible definitions of the concepts of scenography, performance, performativity and theatricality, seeking to establish distinctions and approximations between the performing arts and the visual arts, especially in the field of sculpture. For that, questions raised by authors such as Rosalind Krauss and Josette Féral are analyzed, among others, relevant to the culturally constructed conceptions of these fields and concepts, as well as to the ways of thinking about the making and the creative processes of these areas.

Keywords

Scenography. Theatricality. Performance. Sculpture. 


\section{A problematização}

O presente texto toma por base algumas experiências e questões que me ajudam a pensar os temas propostos, sobre a existência ou não de uma especificidade ou definição da cenografia, tanto do ponto de vista do conceito como também dos modos de pensar e de fazer da cenografia, considerando a atividade criativa e prática dos artistas que a realizam. Este texto também se propõe a contribuir para as discussões levantadas pela $14^{\mathrm{a}}$ edição da Quadrienal de Praga (PQ'), de 2019, na qual se evidencia uma busca da expansão do campo em direção ao que está sendo denominado de desenho de cena.

Segundo a curadora do Brasil da PQ' 2019, Aby Cohen:

[...] é inevitável que neste momento em que as fronteiras de linguagem aparecem borradas e que a necessidade de repensar propostas e processos criativos nas demais disciplinas do desenho da cena se mostra cada vez mais evidente e urgente ${ }^{1}$. (COHEN, 2019. Documento eletrônico).

No seu desejo de buscar borramentos com campos afins, como as artes visuais e o design (afinal, a cenografia originalmente não se localiza no campo do teatro?), a curadoria Brasileira da PQ' 2019 interessou-se por obras de artistas fora do teatro, notadamente do campo das artes visuais, e experiências expositivas que expandem aquilo que hoje se está chamando de desenho de cena, buscando na categoria da performance art outros modos de expor esses trabalhos (fora do palco do teatro), considerando a relação que estas possibilidades estabelecem com o público. Em um artigo escrito por Cohen, chamado A cenografia como performance: influências da quadrienal de Praga, Cohen traz a seguinte provocação de Arnold Aronson, referente à $11^{a}$ edição da Quadrienal de Praga (PQ') realizada em 2007:

1 Texto curatorial da PQ' 2019 Brasil. Disponível em:

<:https://pqbrasil.org/curadoria >. Acesso em 28 set. 2019.
O Teatro tem sido descrito, muitas vezes, como a arte da ausência. O reino visível do palco implica em uma ampla abstração do mundo além. Teatro é estar no palco e nos bastidores - entre o visível e o invisível. [...]. Se a PQ' se coloca como performance e define que o salão de exposição é o seu palco e o conteúdo presente é a cenografia, o que está ausente são as performances, às quais se referem as exposições. APQ' seria meramente uma exposição de objetos - fascinantes, mas desprovida de sentido se não existir um diálogo entre o visível e o invisível. (ARONSON, apud COHEN, 2018, p. 141).

Por trás da ideia de "abstração do mundo além" e da relação entre visível e invisível parece-me que está subjacente a noção de ficção, de narrativa e de representação, que se não é presentificada pela ação teatral, ao menos é evocada por ela.

No exercício de pensamento sobre tal problema, tanto no seu artigo como no texto curatorial da PQ' 2019, Cohen reiteradamente, e de modo que nos parece bem apropriado, associa a cenografia a conceitos como representação, ficção, narrativa, atrelando-a ao ato de contar histórias.

Começamos com a seguinte questão: o que é necessário para que uma expressão artística possa ser chamada de cenografia? Para mim, particularmente, estes questionamentos se fazem pertinentes em relação às práticas artísticas e indagações teóricas que realizamos no Grupo de Pesquisa Insubordinada ${ }^{2}$, o qual coordeno. Investigando e buscando procedimentos criativos que fujam das relações de subordinação entre os elementos e meios expressivos da encenação, evitamos a ilustração e a representação de textos dramatúrgicos prévios, buscando agir criativamente a partir da noção

20 Grupo de Pesquisa Insubordinada atualmente desenvolve o projeto de pesquisa: A operatividade como geradora do processo de criação cênica. 
de operatividade ${ }^{3}$, surgida no decorrer do percurso das experimentações realizadas por mim desde pelo menos duas décadas e pelo grupo a partir de 2015 . Desde 2017 tenho trabalhado na construção do que chamo de estações de trabalho, carrinhos feitos em madeira e dotados de rodas que contém e/ou servem de base para execução de operações e manipulações com equipamentos e objetos diversos, que constituem as investigações cênicas e performáticas que realizo em meu trabalho solo e também com o grupo, resultando em diversos espetáculos e performances realizados de 2015 em diante. Pois, a reflexão sobre esta prática provocou a seguinte indagação: é possível dizer que estas estações de trabalho e estes objetos (ou aparelhos) são cenografia? A partir das colocações acima, trazemos também as seguintes inquirições: quais as relações possíveis entre a cenografia e a performance? São coisas diferentes? Podem ser a mesma coisa?

Penso que estas questões devem ser abordadas de ao menos duas formas: considerar estes termos como associados a categorias artísticas culturalmente e historicamente construídas; e como atividades relativamente específicas dentro das artes, das quais devemos levar em conta o conjunto de considerações e modos de fazer dos seus autores.

Para isto, a partir de questionamentos levantados por Rosalynd Krauss e Josette Féral, buscarem os definir, ou ao menos analisar, os termos 'cenografia', 'performance', sendo que é igualmente importante considerar estes termos aproximando e distinguindo entre o modo como costumam operar dentro das áreas distintas do teatro e das artes visuais. Tomaremos o caso da escultura em particular, tanto pelo fato de que o campo analisado por Krauss, como também porque a performance art, se entendida como categoria consagrada nas artes visuais, esta bastante próxima desta área. Devido às

3 O conceito de operatividade se faz presente quando o processo de criação se dá a partir de operações técnicas e conceituais criativas, antes mesmo que uma elaboração formal ou ficcional se estabeleça. minhas experiências como artista e professor, tanto nas artes visuais como no teatro, escrevo como alguém que habita estes dois lugares, assim como os lugares entre eles. Para tomar de empréstimo e lançar os conceitos de uma área sobre outra devem ser consideradas atentamente e profundamente as razões, questões e argumentos que constituem o conjunto de considerações de cada um destes campos.

\section{— As definições e ampliações dos campos}

Em seu artigo denominado $A$ escultura no campo ampliado, que penso ser fundamental para discutir a ampliação dos campos artísticos, Rosalind Krauss inicia seu raciocínio afirmando o seguinte: "apesar do uso elástico de um termo como escultura ser abertamente usado em nome da vanguarda estética - da ideologia do novo - sua mensagem latente é aquela do historicismo" (KRAUSS, 1984, p. 129). E prossegue:

Entretanto, eu diria que sabe-
mos muito bem o que é uma
escultura. Uma das coisas aliás
que sabemos é que escultura
não é uma categoria universal,
mas uma categoria ligada à
história. A categoria escultura,
assim como qualquer outro tipo
de convenção, tem sua própria
lógica interna, seu conjunto
de regras, as quais, ainda que
possam ser aplicadas a uma
variedade de situações, não
estão em si próprias abertas
a uma modificação extensa.
Parece que a lógica da escultura
é inseparável da lógica do
monumento. (Idem, p. 131).

Ela reconhece que a definição de um gênero ou campo de saber artístico (no caso, a escultura) é grandemente determinado por um consenso desenvolvido ao longo do tempo por seus agentes e pelo público em geral, historicamente integrado à nossa cultura (ocidental). Inicialmente, a escultura (em sua tradição desde a Grécia antiga) se apresenta como 
representação e imitação mimética do 'mundo real'. Avançando em suas colocações, e considerando as mudanças de paradigma da escultura, desde o abandono da noção de representação mimética até o pensamento formal relacional ${ }^{4}$, e para além disso, discutindo a sua ampliação, esta autora faz a seguinte problematização:

A ampliação do campo que
caracteriza este território do
pós-modernismo possui dois
aspectos já implícitos na
descrição acima. Um deles
diz respeito à prática dos
próprios artistas; o outro, à
questão do meio de expressão.
[...] Isto porque, no pós-moder-
nismo, a práxis não é definida
em relação a um determinado
meio de expressão - escul-
tura - mas sim em relação a
operações lógicas dentro de
um conjunto de termos culturais
para o qual vários meios -
fotografia, livros, linhas em
parede, espelhos ou escultura
propriamente dita - possam
ser usados. (Ibidem, p. 136)

Assim, a expansão do campo da escultura, além das abordagens historicistas e culturais, passa pelo conjunto de considerações dos artistas escultores que a praticam. Trataremos aqui da colocação acima para trazer ao nosso raciocínio conceitos ligados às práticas de artistas que, a partir do minimalismo, farão parte dos modos de pensar o fazer da escultura. Para expor o que estamos tratando - uma abordagem tautológica ${ }^{5}$, literal e processual

$4 \mathrm{Em}$ um dos textos que fundamentam a posição do Minimalismo, Frank Stella e Donald Judd (2006) utilizam a expressão não-relacional (non-relational), buscando o valor do objeto de arte na "sua própria especificidade" (JUDD, 2006) e na negação do pensamento formal que se baseia nas relações entre as partes e as partes e o todo, próprio do pensamento da linguagem e da sintaxe visual, questões teoricamente inauguradas pelos artistas modernistas. A expressão relacional não deve ser confundida com a noção de arte-relacional lançada mais recentemente por Nicolas Bourriaud (2009).

5 O termo tautologia é empregado aqui conforme a proposição de Georges Didi-Huberman no livro $O$ que vemos o que nos do fazer da escultura - e acompanhar o exercício de pensamento desta autora, trazemos questões apontadas por Krauss em seu livro Caminhos da escultura moderna, ao discorrer sobre as argumentações dos artistas Donald Judd e Frank Stella:

Em 1964, Donald Judd falou sobre esta qualidade de repetição tanto em sua própria escultura como nas pinturas de Frank Stella. "A ordem", escreveu, "não é racionalista e subjacente, mas é simplesmente ordem, como a da continuidade; uma coisa depois da outra." Algum tempo depois, em uma entrevista coletiva, ele e Stella discorrem mais a fundo sobre o interesse de ambos nessa composição de "uma coisa depois da outra". Tratava-se, afirmaram, de uma estratégia para escapar à composição relacional que identificavam como europeia. (KRAUSS, 1998, p. 292).

Segundo Krauss, estes artistas reagiram contra um ilusionismo escultural (a pedra imitando a forma humana, por exemplo) e contra o pensamento formal relacional, até então motrizes do fazer da escultura. Adentrando ainda mais nestas questões, ela traz o caso exemplar do artista Richard Serra, analisado seu trabalho Placas de aço empilhadas (1969) e as suas $P$ eças moldadas em chumbo, da mesma época, associando-as a uma anotação de trabalho deste artista onde ele elenca uma conhecida lista de verbos:

Ao contemplar esse encadeamento de verbos transitivos, cada qual especificando uma ação particular a ser desenvolvida sobre um material não-especificado, percebemos a distância que o separa do que normalmente esperaríamos encontrar no caderno de anotações de um escultor. Em

olha (1998), referindo-se aos aspectos factuais e concretos das obras do minimalismo, opondo-os em uma relação dialética ao conceito de crença. 
lugar de um inventário de formas, Serra registra uma relação de atitudes comportamentais. Percebemos, contudo, que estes verbos são, eles próprios, os geradores de formas artísticas: são como máquinas que, postas em funcionamento, têm a capacidade de construir um trabalho. (Idem, p. 331).

Considerando-se as colocações de Krauss, pode-se pensar que Richard Serra é um destes artistas motivados pelos modos de pensar e de fazer da escultura, e que tais preocupações assumem um sentido fundamental nas suas realizações artísticas. Assim, a ampliação das práticas e dos modos de pensar "o fazer" acabaram também por ampliar o conceito e a definição da escultura, forçando o campo cultural das artes a acompanhar tal alargamento.

Antes de avançarmos na discussão sobre possíveis definições e a consequente ampliação do conceito de cenografia, é interessante mencionar que a abordagem operativa que adotamos em nossa pesquisa está profundamente ligada e é devedora das considerações colocadas logo acima. Privilegiamos o processo criativo que parte das operações (ações e procedimentos práticos), deixando que as formas e resultados estéticos, bem como a dramaturgia, sejam resultantes ou disparadas por estes processos. Pensamos que antes de serem cenografia, as nossas estações de trabalho sejam, de acordo com Krauss, "máquinas que, postas em funcionamento, têm a capacidade de construir um trabalho" através das operações realizadas com elas.

Josette Féral é uma conhecida pensadora que aborda as relações e diferenças entre teatralidade e performatividade. No exercício de seu pensamento ela traz cogitações pertinentes para as nossas questões. Assim como Krauss, esta autora também trata tanto da definição como da ampliação dos conceitos de teatralidade, de teatro, de performance e, na esteira destes raciocínios, de cenografia. Segundo ela:
A emergência da teatralidade em outros espaços que não o teatro parece ter por corolário a dissolução dos limites entre os gêneros e das distinções formais entre as práticas: da dança-teatro às artes multimídia, passando pelos happenings, a performance, as novas tecnologias, é cada vez mais difícil determinar as especificidades. À medida que o espetacular e o teatral passaram a fazer parte de novas formas, o teatro, repentinamente descentrado, foi obrigado a se redefinir. A partir daí, perdeu suas certezas. (FÉRAL, 2015, p. 82).

Podemos verificar aí, mais uma vez, a necessidade e a dificuldade da definição do campo do teatro. Mas quais seriam estas certezas perdidas mencionadas por ela?

Atrelado a esta delimitação do campo do teatro, Féral traz uma consideração sobre a cenografia que julgamos ser importante:

\begin{abstract}
Vocês entram em um teatro onde determinada disposição cenográfica está, evidentemente, à espera do início da representação; o ator está ausente; a peça não começou. Pode-se dizer que existe aí teatralidade? Responder de modo afirmativo é reconhecer que a disposição "teatral" do lugar cênico traz em si certa teatralidade. $O$ espectador sabe o que esperar do lugar e da cenografia: teatro. (Idem, p. 84).
\end{abstract}

Deste trecho citado, observamos que a noção de teatro está vinculada também a um tipo de edifício cênico cujo formato de palco associa-se ao que é vulgarmente chamado de "palco italiano", cujas características estão ligadas à frontalidade da cena e à separação entre palco plateia, algo que se consolidou na cultura ocidental a partir do século XVI (cujo apogeu ou "maturidade" é encontrado a partir do século XIX no teatro Wagneriano, quando, 
entre outros aspectos, se apagou a luz da plateia), no qual se consolidou a noção de que o público frequenta este espaço para assistir a um espetáculo que trará a representação de uma história ou narrativa encenada por atores que encarnam personagens fictícios (um drama, no sentido clássico ou classicista da expressão). Considerando esta concepção de palco e de teatro, poderíamos entender a cenografia como uma encarnação espacial e visual do lugar onde se passa o drama, sendo um dos elementos ou um dos instrumentos da ficção.

Prosseguindo nas suas colocações, Féral traz a questão da intencionalidade para a definição do teatro e da teatralidade. A partir de um dos exemplos dos quais a autora lança mão para desenvolver seu argumento, ela diz que

A teatralidade, nesse caso, parece ter surgido do conhecimento do espectador, desde que foi informado da intenção de teatro em sua direção. Esse saber modificou seu olhar e forçou-o a ver o espetacular onde então só havia o especular, ou seja, o evento. Ele transformou em ficção o que pensava surgir do cotidiano; [...] (Ibidem, p. 85).

A questão da intencionalidade para a caracterização da arte é colocada por Pierre Bourdieu ao analisar a diferença entre o modo de percepção estético e o modo de percepção prático (cotidiano) no livro A economia das trocas simbólicas:

Se aceitarmos a colocação de Panofsky, de que a obra de arte é o que exige uma apreensão guiada por uma intenção estética (demands to be experienced esthetically) e, de outo lado, se todo objeto, natural ou artificial, pode ser percebido segundo uma intenção estética, de que maneira pode-se escapar à conclusão de que é a intenção estética que "faz" uma obra de arte, ou melhor, transpondo-se a fórmula de Saussure, de que é ponto de vista estético que cria o objeto estético? (BOURDIEU, 2001, p. 270).

Entra em questão aqui a diferenciação entre arte (ou estética) e cotidiano, o que entendemos como um entendimento cultural (porque é uma definição construída a partir da delimitação dos campos de conhecimento estipulados na lógica ocidental) do que seja ou não seja arte (ou teatro, no caso de Féral), muito embora não devamos deixar de considerar as repercussões filosóficas da intencionalidade, tendo em vista que tal noção de arte traz em seu bojo um olhar diferenciado, investigativo e crítico do mundo concreto.

Prosseguindo com os argumentos de Féral:

Nesse caso, a teatralidade surge a partir do performer e de sua intenção expressa de teatro. Mas é uma intenção que o espectador deve conhecer, necessariamente, sem o que não consegue notá-la, e a teatralidade lhe escapa. (FÉRAL, 2015,. p, 85).

E o reconhecimento do teatro e da teatralidade é de muitas formas dependente do espaço convencionado e institucionalizado do edifício teatral (portanto, de uma abordagem cultural), de modo similar ao que faz um museu ou galeria de arte em relação às artes visuais, pois

A condição à teatralidade seria, portanto, a identificação (quando é produzida pelo outro) ou a criação de um "outro espaço", espaço diferente do cotidiano, criado pelo olhar do espectador que se mantém fora dele. Essa clivagem no espaço é o espaço do outro, que instaura um fora e um dentro da teatralidade. (Idem, p. 86). 
Esta autora prossegue problematizando ainda mais esta questão:

Se a condição sine qua non da teatralidade, como acabamos de defini-la, é a criação de outro espaço onde a ficção pode surgir, essa característica não nos parece específica do teatro. Então quais seriam os signos característicos da especificidade cênica? O que apenas o teatro consegue produzir? (Ibidem, p. 90).

Uma possível resposta a esta questão, apontada por Féral, estaria então na relação entre o tripé formado pela presença do ator, da ficção e do jogo, sendo que, resumidamente, o jogo é aquilo que se estabelece entre $o$ ator (juntamente com os demais elementos cênicos, incluindo a cenografia) e a ficção. Estabelecendo-se então um jogo entre a concretude real do ator e dos elementos da encenação, que estão presentes (assim como o público), e a narrativa ficcional, teríamos a circunstância necessária para se instalar a teatralidade.

Se aceitamos que este é um entendimento historicamente e culturalmente construído, restar-nos-ia dizer que existe cenografia quando ocorre essa ligação triádica entre a presença concreta dos elementos cenográficos e a ficção (representação), e o jogo que se estabelece entre estes dois.

\section{A cenografia e o desenho de cena}

A partir dessa caracterização proposta por Féral, podemos retomar os questionamentos e as práticas trazidos pelas edições recentes das PQ's, mencionadas no artigo de Aby Cohen. Respondendo à colocação de Arnold mencionada neste artigo, Cohen afirma o seguinte:

Diante de experiências relevantes, vivenciadas no contexto da Quadrienal de Praga e fora dela, os projetos que desenvolvi como curadora e cenógrafa - a exemplo de Personagens e Fronteiras: Território Cenográfico Brasileiro na PQ2011, SharedSpace/Politics e No Man's Land na PQ2015, Desenhos de Cena \#1 e Cena \#2: WSDesign Playground, em 2016 e 2017 respectivamente - revelam a inquietude, como cenógrafa, em explorar e atuar no campo em que a cenografia deixa de ser mero suporte para uma cena ter lugar, assumindo suas qualidades narrativas e independência, potencializada e explorada para apresentar-se como performance. (COHEN, 2018, p. 142).

Parece-me que para que os trabalhos mencionados por Cohen respondam à Arnold é necessário entendermos o modo que ambos utilizam o termo performance. No Projeto de Curadoria para a PQ2019, a curadora apresenta o desenho de cena como um ponto de convergência entre o teatro, as artes visuais e a performance, apontando para "obras de artistas fora do teatro, do campo das artes visuais e da performance". Então, podemos entender a partir dessa proposição que teatro, artes visuais e performance são campos distintos? A distinção entre teatro e performance é abordada por autores como Féral, a partir da presença da narrativa (mesmo que não-textual) no primeiro, como representação de algo, e da ausência da narrativa na segunda, como apresentação de algo factual. $\mathrm{O}$ teatro performativo estaria (aqui, temos performance em uma concepção adjetiva, e não substantiva), portanto, numa condição intermediária entre estas concepções. Entretanto, assumo aqui a atitude de pensar a arte da performance como uma categoria surgida nas artes visuais e que, portanto, não está separada deste campo. Esta é uma posição central para prosseguir nos argumentos que apresentarei a seguir. Antes mesmo de adentrar na complexa tarefa de uma possível definição da noção de performance, ao menos como uma categoria artística (perfor- 
mance art), primeiramente podemos pensar que as obras mencionadas por Cohen podem de fato ser consideradas como cenografia, se entendermos que quem a realiza, quem "atua", é o público, que realiza o diálogo entre "o visível e o invisível" dotando a instalação do sentido exigido por Arnold. Nos desenhos de cena citados, a camada ficcional está presente através da temática de cada montagem, expressa por objetos e imagens figurativas (elementos não textuais e não verbais) e pelo espaço penetrável.

Se aceitamos que o público possa assumir a função do ator nesses desenhos de cena, então também teremos o tripé definidor da teatralidade proposto por Féral, e eles podem sim ser considerados como cenografia.

Tendo colocado isto, resta mencionar a segunda abordagem que nos propomos analisar aqui, no sentido tanto de definir como de ampliar o campo da cenografia: se os modos de fazer e de pensar o fazer também definem um campo de saber e uma categoria artística, como um cenógrafo pensa a sua prática?

Pela minha própria experiência, seja como artista seja como professor pesquisador, diria que existem ao menos duas posições apriorísticas em relação a isso: aquela dos cenógrafos que pensam por projeto, como é comum por parte daqueles que chegaram à cenografia por intermédio dos campos da arquitetura e do design, e aquela dos cenógrafos que pensam pela experiência direta com os materiais, como é mais comum no caso dos que chegam a esta área através das artes visuais, sem que estes dois casos sejam necessariamente excludentes ou exclusivos de cada postura. Esta problematização traz ainda muitas questões, desde o problema da autoria (referente à produção de sentido da obra e da dramaturgia), da hierarquização do sistema de produção da cenografia e do teatro, e dos processos de criação da cenografia. Faz bastante sentido, para mim, considerar a diferença entre atender uma demanda de sentido externa e anterior à produção da cenografia (as concepções e ideias do diretor, o texto dramatúrgico previamente elaborado, por exemplo) e a possibilidade da criação da dramaturgia e do sentido da obra a partir das elaborações cenográficas e dos objetos de cena. Para pensar a diferença entre executar e pensar uma criação para atender uma ideia previamente fixada (ainda que de modo não fechado) e executar e pensar o fazer de um trabalho a partir dos materiais e das circunstâncias concretas (quando a construção técnica, a experimentação, a manipulação e as operações realizadas com os materiais e objetos é que disparam os sentidos dramatúrgicos e ficcionais), trago para a discussão as noções de imaginação formal e de imaginação material propostas por Gaston Bachelard (1997). Para ele, a primeira valorizaria a criação como um projeto mentalmente e previamente concebido, restando apenas a sua execução formal e material. A segunda coloca a criação como trajeto, como fruto do embate do artista com seus materiais. Entendo que a imaginação material está de acordo com o conceito de operatividade, que adotamos na nossa pesquisa, e tem familiaridade com as questões colocadas por Rosalind Krauss ao tratar dos processos de criação dos artistas do minimalismo e de Richard Serra.

Também podemos considerar que, se desejamos ampliar as concepções e a definição do campo da cenografia, estes diversos modos de praticar e de pensar o fazer da cenografia tem algo a contribuir.

\section{O caso da performance: pontos de vista das} artes visuais e das artes cênicas

O termo performance é utilizado muitas vezes como sinônimo de espetáculo ou de acontecimento espetacular. Os modos mais comuns de uso do termo, conforme nos lembra Josette Féral, podem ser identificados nos casos da arte da performance (performance art), que acabou por constituir um gênero ou categoria presente no campo das artes visuais pelo menos desde a década de 1960 (embora a prática da performance art anteceda o surgimento desta palavra), e também no seu 
uso como "ferramenta teórica de conceituação do fenômeno teatral" (FÉRAL, 2008, p. 197), como no emprego que Richard Schechner dá ao termo.

Schechner ampliava ali a noção para além do domínio artístico para nela incluir todos os domínios da cultura. Em sua abordagem, a performance dizia respeito tanto aos esportes quanto às diversões populares, [tanto] ao jogo [quanto] ao cinema, [tanto] aos ritos dos curandeiros ou de fertilidade [quanto] aos rodeios ou cerimônias religiosas. (FÉRAL, 2008, p. 198).

Para nossa argumentação, a abordagem de Schechner é abrangente demais para que seja utilizada na análise das questões relacionadas à arte da performance, que auxiliariam a traçar diferenças fundamentais entre as artes visuais e as artes cênicas.

Ele apresenta a noção de performance relacionando-a também aos negócios, os esportes, o sexo, e à vida cotidiana, entendendo que "nas artes, 'realizar performance' é colocar esta excelência em um show, numa peça, numa dança, num concerto" (SCHECHNER, 2006, p. 28). Assim, fica evidente que este autor aproxima a performance "nas artes" cênicas mais do que nas artes visuais, embora reconheça que "algo é performance quando os contextos histórico e social, a convenção, o uso, a tradição, dizem que é" e, portanto, "não se pode determinar o que "é" performance sem antes se referir às circunstâncias culturais específicas". (Idem, p.38).

A abertura do termo proposta por ele em relação a outros campos da cultura e das atividades humanas pode ser compreendida como um ponto de contato entre as categorias artísticas, uma vez que traz componentes antropológicos e sociológicos que ultrapassam essas barreiras. Mas se buscarmos entender a performance art como uma categoria surgida nas artes visuais, sua abordagem nos é menos útil.

Ainda segundo Féral, as distintas abordagens
[...] emergem, por meio destas duas visões de performance uma herdada da vanguarda e da arte da performance (a de Huyssen e de tudo que poderei chamar, para ser breve, de tradição européia dos países latinos), a outra herdada de uma visão antropológica e intercultural com a qual Schechner contribui fortemente para sua difusão - os dois grandes eixos a partir dos quais podemos pensar o teatro - e, mais amplamente, as artes - hoje. (FÉRAL, 2008, p. 200).

Se a nossa intenção é de buscar aproximações entre os campos artísticos que considerem as suas diferenciações e especificidades, um ponto a ser destacado é a relação que a arte da performance estabelece com o estatuto, a definição e a reconhecibilidade do objeto artístico na cultura ocidental. A obra de arte (uma pintura ou uma escultura, por exemplo) nas artes visuais costumava ser permanente, duradoura (e colecionável). Sendo assim, a performance surge como rompimento desta tradição. Por outro lado, nas artes cênicas, a efemeridade da performance está de acordo com a efemeridade do espetáculo cênico e, portanto, ao menos neste aspecto, não "ameaça" o estatuto da obra teatral. A prática da performance nas artes visuais correspondeu em grande parte à tentativa de negação da arte como produto ou mercadoria feita por parte das vanguardas tardias do modernismo. Destarte penso que a categoria performance tem um sentido e uma razão de ser diferente em cada uma dessas áreas. Nas artes visuais, a "desmaterialização" da obra de arte, nome que os teóricos Lucy Lippard e John Chandler (2013) deram a este fenômeno, perpassou a consideração e orientou a prática de muitos artistas e críticos na década de sessenta, evolvendo a noção de arte processual, abarcando a performance, o happening, a land art, a art povera e a body art, por exemplo.

$\mathrm{Na}$ esteira das diferenças, os modos de pensar o fazer da performance no teatro e nas artes visuais também apresentam aspectos distintos, embora 
existam atravessamentos e conexões. Uma motivação consideravelmente significativa para a emergênvém do entendimento da arte como ação, como um fazer operativo (como processo e não como produto) que nega os princípios de representação mimética e do pensamento formal, que identificamos acima nos apontamentos de Rosalind Krauss sobre os minimalistas e sobre Richard Serra, somados às proposições de artistas como Alan Kaprow ${ }^{6}$ e os integrantes do movimento Fluxus ${ }^{7}$. Todos estes defendiam e orientavam o pensamento do fazer do seu trabalho na direção oposta e na negação da ficção e da representação, distanciando-se desta maneira de pelo menos um dos elementos essenciais do tripé identificador da teatralidade sugerido por Josette Féral.

Referindo-se à performatividade, ela identifica a origem deste termo da seguinte maneira:

[...] de uso quase exclusivamente norte-americano (mesmo se Lyotard utiliza o termo), sua origem poderia ser retraçada nas pesquisas lingüísticas de Austin e Searle, que foram os primeiros a impor o conceito pelo viés dos verbos performativos que "executam uma ação". Eis uma primeira consideração. Essa noção valoriza a ação em $\mathrm{si}$, mais que seu valor de representação, no sentido mimético do termo. O teatro está inexoravelmente ligado à representação de um sentido, passe ele pela palavra ou pela imagem. O espetáculo nele segue uma narrativa [récit], uma ficção. (FÉRAL, 2008, p. 201).

6 No texto O legado de Jackson Pollock, Kaprow (2006) identifica no modo de pintar deste artista - considerando o ato de fundamental que o influenciaria na criação e conceituação dos seus Happenings.

7 Além da noção de arte como ação, Kaprow e o Fluxus tem em comum o borramento dos limites entre arte com o cotidiano. cia da categoria performance nas artes visuais propintar mais importante do que o seu resultado - um princípio

Ora, se a performance como categoria artística surgida no campo das artes visuais tem como princípio a negação da representação e da ficção, parece-nos que noção de performance relacionada às mostras de cenografia, ou desenho de cena realizadas na PQ de 2015 e 2019 apresenta alguma dificuldade para que seja associada à performance como categoria artística das artes visuais, permanecendo assim no campo do teatro, muito embora, novamente segundo Féral, no "teatro performativo"

[...] o ator é chamado a "fazer" (doing), a "estar presente", a assumir os riscos e a mostrar o fazer (showing the doing), em outras palavras, a afirmar a performatividade do processo. A atenção do espectador se coloca na execução do gesto, na criação da forma, na dissolução dos signos e em sua reconstrução permanente. Uma estética da presença se instaura (se met en place). (FÉRAL, 2008, p. 209).

Distanciar-se da ficção (mas sem escapar totalmente dela) é uma característica do teatro performativo. Não devemos esquecer que esta autora procura estabelecer diferenciações e oposições entre teatralidade e performatividade, e que a ênfase ou não na ficção representacional é uma das chaves desta diferenciação. Sobre o teatro performativo, ela diz que este existe há algum tempo nos palcos, mas somente foi definido como "pós-dramático" por Hans Thies Lehmann (2007, p. 197) em 1999.

Nas suas considerações feitas em seu livro sobre o teatro pós-dramático, Lehmann reconhece que um pouco tardiamente

Resgata-se no campo do teatro
um desenvolvimento estético
pelo qual outras artes tinham
passado antes. Não é por acaso
que conceitos provenientes das
artes plásticas, da música e
da literatura são apropriados
para caracterizar o teatro 
pós-dramático. [...] Com uma frequência notável, importantes artistas teatrais da atualidade têm uma experiência prévia com as artes plásticas. Não é de admirar que apenas no teatro das últimas décadas foram "alcançadas" as empreitadas que podem ser evocadas com palavras-chave como autoreferência, não-figuração, arte abstrata ou concreta, autonomização dos significantes, serialidade, aleatoriedade, etc. (LEHMANN, 2007, p. 155).

$\mathrm{Na}$ busca por uma posição não-dramática, associada à arte concreta, a arte da performance originada nas artes visuais se afasta da ficção e da representação mimética, distanciando-se da teatralidade e, sendo assim, os artistas que praticam a performance advindos das artes visuais costumam partir de concepções e considerações distintas daquelas dos cenógrafos.

\section{Considerações finais}

Parece inegável, para que haja o mínimo de rigor no exercício das ampliações das noções e conceitos dos campos, que estas paradoxalmente exijam a tentativa das suas definições e de distinções.

Poderíamos dizer, tomando a formulação de Féral no caso dos projetos de cena de Cohen (2018, p.142), que "a cenografia deixa de ser mero suporte para uma cena ter lugar, assumindo suas qualidades narrativas e independência", para apresentar-se "como teatro em si". O próprio termo "cenografia" está conectada ao pensamento teatro, e não constitui uma questão própria das artes visuais, salvo em usos superficiais ligados ainda ao entendimento da arte como representação. O termo performance, por outro lado, se estende à diversos campos de saber. Mas o entendimento da performance como um tipo de arte, uma categoria, tem forte pertencimento às cogitações das artes visuais, como nos propomos a demonstrar.
Schechner afirma que "existem limites para o que é performance. Mas quase tudo que existe pode ser estudado enquanto performance" (SCHECHNER, 2006, p. 38). Ao invés de nos perguntarmos o que define cada categoria (o que é cenografia? O que é performance?), poderíamos perguntar quando e em que circunstâncias tais delimitações se tornam possíveis (Quando é cenografia? Quando é performance?). Assim, seria possível afirmar, ao menos no caso das estações de trabalho que participam da nossa prática de pesquisa cênica, que estas podem se tornar cenografia no momento em que os sentidos ficcionais e dramatúrgicos são posteriormente atribuídos ou associados a elas. Talvez este não seja o caso de uma dramaturgia da cenografia, posto que as estações de trabalho não surgem de início como cenografia, mas antes de uma dramaturgia operativa.

Diante do exposto acima, é possível pensar que a cenografia está ontologicamente vinculada à noção de teatralidade, pelo seu vínculo histórico e originário com a ficção e a representação, afastando-se assim da categoria artística da performance, que ontologicamente está enraizada na negação da representação nas artes visuais iniciada no modernismo. Por tais motivos é que os modelos de análise mencionados neste texto colocam a performance em um lado oposto ao do teatro.

Mas se a cenografia não se coloca ao lado das questões da performance art, aceitemos que ela pode ser ao menos entendida enquanto performance em outras situações. Pois, ainda conforme Schechner, olhar algo "enquanto" performance, é "investigar o que faz o objeto" para "olhar para as coisas que, de outra maneira, estariam fechadas para investigação" (Idem, p. 49). 


\section{Referências}

BACHELARD, Gaston. A água e os sonhos: ensaio sobre a imaginação da matéria. São Paulo: Martins Fontes, 1997.

BOURDIEU, Pierre. A economia das trocas simbólicas. São Paulo: Perspectiva, 2011.

BOURRIAUD, Nicolas. Estética relacional. São Paulo: Martins Fontes, 2009.

COHEN, Aby. A cenografia como performance: influências da Quadrienal de Praga. Revista do Centro de Pesquisa e Formação / ${ }^{\circ} 6$. São Paulo: SESC, junho 2018. Disponível em: < https://www.sescsp.org. br/files/artigo/a905bd03/ee2b/467c/872b/0fd58bf6bb85.pdf >. Acesso em: 25 Set. 2019.

DIDI-HUBERMAN, Georges. O que vemos o que nos olha. São Paulo: Ed. 34, 1998.

FÉRAL, Josette. Por uma poética da performatividade: o teatro performativo. In Revista Sala Preta, no 8, 197-210. São Paulo: USP, 2008. Disponível em: htttp://revistas.usp.br/salapreta/article/ view/57370/60352. Acesso em: 25 de Set. 2019.

FÉRAL, Josette. Além dos limites: teoria e prática do teatro. São Paulo: Perspectiva, 2015.

FRIED, Michael. Arte e objetividade. In Revista de Pós Graduação em Artes, EBA, UFRJ, 2002. Disponível em: < https://www.ppgav.eba.ufrj.br/ wp-content/uploads/2012/01/Arte-e-objetidade-Michael-Fried.pdf >. Acesso em: 25 set. 2019.

INSTALAÇÃO. In: ENCICLOPÉDIA Itaú Cultural de Arte e Cultura Brasileiras. São Paulo: Itaú Cultural, 2019. Disponível em: < http://enciclopedia.itaucultural.org.br/termo3648/instalacao >. Acesso em: 28 set. 2019. Verbete da Enciclopédia.

JUDD, Donald. Objetos específicos. In COTRIM, Cecilia e FERREIRA, Gloria. Escritos de Artistas - Anos 60/70. Rio de Janerio: Zahar, 2006, p. 96-106.

KAPROW, Alan. O legado de Jackson Pollock. In COTRIM, Cecilia e FERREIRA, Gloria. Escritos de Artistas - Anos 60/70. Rio de Janerio: Zahar, 2006, p. 37-45.
KRAUSS, Rosalind. A escultura no campo ampliado. In Revista Gávea, no 1, Rio de Janeiro: PUC, 1984. Disponível em: https://monoskop.org/images/b/bc/ Krauss_Rosalind_1979_2008_A_escultura_no_ campo_ampliado.pdf. Acesso em: 25 Set. 2019.

KRAUSS, Rosalind. Caminhos da escultura moderna. São Paulo: Martins Fontes, 1998.

LEHMANN, Hans-Thies. Teatro pós-dramático. São Paulo, Cosac\&Naify, 2007.

SCHECHNER, Richard. 2006. O que é performance. In: Performance studies: an introduction, second edition. New York \& London: Routledge, p. 28-51.

LIPPARD, Lucy R.; CHANDLER, John. A desmaterialização da arte. In: Arte \& ensaios, revista do ppgav/ eba/ufrj, n. 25, maio 2013. Disponível em: < https:// www.ppgav.eba.ufrj.br/wp-content/uploads/2013/12/ ae25_lucy.pdf >. Acesso em 25 Set. 2019.

STELLA, Frank; JUDD, Donald. Questões para Stella e Judd. In: COTRIM, Cecilia e FERREIRA, Gloria, p. 122-138. Escritos de Artistas - Anos 60/70. Rio de Janerio: Zahar, 2006.

Recebido: 29/09/2019

Aprovado: 24/03/2020 